Trab. Ling. Aplic., Campinas, 45(1): 119-134, Jan./Jun. 2006

\title{
A CORREÇÃO DE ERROS COMO CO-CONSTRUÇÃO DE CONHECIMENTO NA AULA DE LÍNGUA ESTRANGEIRA (INGLÊS)
}

\author{
FRANCIELI FREUDENBERGER \\ MARÍLIA DOS SANTOS LIMA \\ UNIJUÍ
}

\begin{abstract}
RESUMO
O principal objetivo deste trabalho é analisar o papel da correção de erros, considerada um componente intrínseco do ensino de uma segunda língua, na interação entre professor e alunos em sala de aula de inglês como língua estrangeira. Além disso, procura-se examinar em que medida a realização de uma correção com foco formal pode representar momentos de co-construção de conhecimento da língua alvo. A pesquisa foi realizada por meio da observação de aulas de inglês de uma turma do sexto semestre de um curso de licenciatura em Letras Língua Inglesa. Os dados indicam que, por meio da correção da forma lingüística, os enunciados produzidos pelos aprendizes, mesmo quando formalmente inadequados, podem ser recontextualizados e incorporados ao discurso da sala de aula. Por outro lado, os resultados apontam que, mesmo quando a interação possui características de instrução tradicional (cf. Gil, 1999), o conhecimento da língua alvo pode ser construído pela professora e aprendizes.
\end{abstract}

Palavras-chave: tratamento corretivo; co-construção; aprendizagem

\begin{abstract}
The main purpose of this paper is to analyze the role of error correction, seen as an intrinsic component of second language teaching, in the interaction between teacher and students in an English as a Foreign Language class. Moreover, it is intended to examine the extent to which the act of correcting a formal/linguistic error can constitute a moment of co-construction of target language knowledge. The research was done through the observation of English classes in a group attending the sixth semester of a university English language course. The data indicate that, through formal correction, the statements produced by the learners, even when linguistically inadequate, may be recontextualized and incorporated in the classroom discourse. On the other hand, the results point out that even when the interaction possesses traditional instruction characteristics (cf. Gil, 1999), target language knowledge may be constructed by teacher and learners.
\end{abstract}

Key-words: error treatment; co-construction; learning

\section{INTRODUÇÃO}

Na área de aquisição de Segunda Língua/Língua Estrangeira (L2/LE), alguns assuntos são considerados controversos e são alvos constantes de pesquisas e debates. Um desses tópicos é, desde a década de 60, a correção de erros. Foram registradas diversas posições que se intercalaram entre defender a validade dessa prática pedagógica e acusá-la de 
retrocessos no processo de aprendizagem da língua alvo. Dependendo da posição adotada, os pesquisadores poderiam prescrever maneiras de proceder perante o erro do aluno: ignorálo, corrigi-lo imediatamente, induzir a auto-correção, para citar apenas algumas sugestões encontradas na literatura (cf. Chaudron, 1988 e Allwright e Bailey, 1991, por exemplo).

No entanto, muitas dessas visões de ensino de línguas e, portanto, de interação em sala de aula vêm sendo desafiadas pela Abordagem Sociocultural. Essa teoria tem por base os pressupostos da teoria vygotskiana (Lantolf e Appel, 1994), sendo que uma de suas principais propostas parece ser deixar de considerar o ensino e a aprendizagem de uma língua enquanto dois fenômenos distintos, em que um é considerado a consequiência do outro. Pelo contrário, os estudos socioculturais procuram investigar o aprender e o ensinar enquanto processos significativos, procurando compreender suas diferentes dimensões. Assim, também a visão sobre correção de erros começa a ser desafiada e recontextualizada.

Considerando, desse modo, a correção de erros lingüísticos um componente intrínseco do ensino de uma segunda língua em sala de aula, o principal objetivo deste estudo é visualizar qual é a participação da prática corretiva na interação entre professor e alunos em sala de aula, ou seja, identificar o seu resultado discursivo.

Para tanto, são apresentadas as seguintes perguntas que guiam a realização desta investigação:

1. Qual é a função desempenhada pela correção de erros na interação entre professor e alunos em sala de aula?

2. A interação que acontece a partir da correção de erros pode representar momentos de co-construção do conhecimento da LE entre professor e aprendizes?

Assim, este trabalho apresenta, primeiramente, um breve histórico sobre o papel da correção do erro nos estudos de aquisição de linguagem. Em seguida, são feitas algumas considerações a respeito da Abordagem Sociocultural no que concerne possíveis relações com o erro lingüístico e sua correção. Seguindo essa parte que traz o embasamento teórico para a realização do trabalho, são apresentados o contexto de pesquisa, os resultados e considerações finais desta.

\section{AS PERSPECTIVAS TEÓRICAS: ANÁliSE CONTRASTIVA E ANÁlISE DE ERROS}

Os erros cometidos pelos aprendizes de LE vêm, de longa data, intrigando professores e pesquisadores interessados em compreender a aquisição de uma língua. Uma das primeiras tentativas de explicação do erro foi feita, ainda na década de 60, pela Análise Contrastiva, que procurava prever quais erros os aprendizes cometeriam, tendo como base a comparação entre a língua materna (LM) e a LE. Essa abordagem, sendo influenciada pelo movimento behaviorista da psicologia, tem como principal pressuposto a concepção que a principal causa das produções errôneas em uma L2 é a transferência dos hábitos anteriormente formados na primeira língua para sua produção na língua alvo (cf. Ellis, 1994). 
Trab.Ling.Aplic., Campinas, 45(1) - Jan./Jun. 2006

No entanto, muitos dos erros previstos pela Análise Contrastiva não eram observados nas trajetórias de aprendizagem, enquanto eram percebidos diferentes erros em áreas consideradas "fáceis" ou "não problemáticas" da língua. Esses fatos demonstraram a incongruência dessa abordagem e levaram ao seu descrédito. Colaboraram ainda para a superação desse paradigma metodológico todas as críticas feitas ao behaviorismo, especialmente o argumento que a aquisição da LM não acontece pela formação de hábitos, mas pela construção criativa de regras mentais, fato evidenciado nos "erros" típicos de crianças não encontrados na fala dos adultos.

A partir dessas constatações, percebeu-se a necessidade de olhar especificamente para a língua produzida pelo aprendiz de LE a fim de compreender quais seriam essas regras mentais originárias de determinados erros. No final da década de 60 surge a Análise de Erros, uma abordagem de pesquisa que procurava investigar não apenas a origem dos erros lingüísticos produzidos pelos aprendizes como também suas conseqüências na aprendizagem da língua alvo. A observação da aprendizagem natural de L2 teve participação decisiva na constituição desse paradigma, uma vez que ela ocorre de maneira bem sucedida mesmo sem correção explícita das estruturas. Novamente a própria percepção do que seria erro e da melhor maneira como tratá-lo modificou-se a partir dessas considerações. Não mais se defendia que os erros deveriam ser evitados e corrigidos imediatamente, para evitar a formação de hábitos não apropriados à LE. A visão durante esse período era exatamente a oposta: corrigir os erros poderia trazer prejuízos ao aprendiz, devendo ser evitada.

Essa última crença/recomendação tornou-se ainda mais contundente no período da versão forte da Abordagem Comunicativa. Representativo desse período é o trabalho de Krashen (1982) defendendo a visão de que apenas o insumo compreensível seria suficiente para a aquisição de uma LE. A partir dessa constatação, vários cursos de idiomas e escolas passaram a adotar um "método natural" para o ensino de línguas, no qual a atenção explícita às formas lingüísticas e a correção dos erros lingüísticos não eram bem vindas em sala de aula. De certo modo, essa foi uma tentativa de aproximar o contexto instrucional de LE aos ambientes de aquisição não formais.

Nesses ambientes instrucionais era constatado um desenvolvimento considerável da fluência dos aprendizes. Entretanto, ainda eram observadas dificuldades na comunicação, especialmente quanto à acurácia lingüística (cf. Harley, 1993). Passou a haver, então, questionamentos de professores e pesquisadores sobre os motivos dessa aquisição parcial da língua alvo. Observou-se que oportunizar aos aprendizes a reflexão e o trabalho com formas lingüísticas quando integradas ao contexto comunicativo de ensino e aprendizagem, poderia trazer benefícios e possibilitar a superação dessas falhas (Swain 1995; 2001). Esse novo movimento ficou conhecido como Foco na Forma. 


\section{FOCO NA FORMA}

De acordo com essa perspectiva metodológica, devem ser prioridade na sala de aula de LE as oportunidades de usar a língua em situações significativas (cf. Doughty e Williams, 1998, que trazem pesquisas e discussões relevantes ao Foco na Forma implementado em sala de aula). Por tal motivo, essa posição é reconhecida como uma versão mais fraca da Abordagem Comunicativa, propondo que

acurácia, fluência e habilidades comunicativas gerais são, provavelmente, melhor desenvolvidas por meio de instrução que seja, fundamentalmente, baseada no significado mas que, em sua orientação, sejam fornecidas atividades oportunas com foco na forma e correção no contexto (Lightbown e Spada 1990:443).

Também a discussão em torno do lugar da correção do erro lingüístico na sala de aula de LE é retomada nesses estudos. Novamente, é sugerido que a correção é "pragmaticamente praticável, potencialmente eficaz e, em alguns casos, necessária" (Lyster, Lightbown e Spada, 1999:457). Isso não representa, no entanto, uma simples volta à Análise de Erros. Os estudos sobre Foco na Forma procuram considerar o erro em si e os movimentos corretivos (ou ações corretivas) que dele se desenvolvem, proporcionando uma visão mais ampla da situação na qual esses eventos acontecem e da produção lingüística do aprendiz.

Atualmente são desenvolvidos diversos estudos que procuram determinar a eficácia e os efeitos dos movimentos corretivos utilizados pelos professores no desenvolvimento da competência lingüística dos aprendizes de LE. Dois tópicos são particularmente recorrentes nessas pesquisas, quais sejam: o uptake do aprendiz a diferentes tipos de correção e a relação entre correção e aprendizagem. $\mathrm{O}$ termo foi introduzido nas pesquisas sobre movimentos corretivos por Lyster e Ranta (1997) e definido por esses autores como "um enunciado do aprendiz que segue imediatamente ofeedback do professor e constitui uma reação à intenção do professor em direcionar atenção a algum aspecto do enunciado inicial do aprendiz" (p. 49). A definição apresentada, bem como o modelo de análise proposto naquele trabalho, são utilizados em diversos trabalhos subseqüentes no Canadá e no Brasil (Panova e Lyster, 2002; Lima, 2002; Menti, 2003 e Freudenberger e Lima, 2003, por exemplo).

Ao ser corrigido, segundo Lyster e Ranta (1997) o aprendiz pode, minimamente, reagir de duas maneiras diferentes: reconhecer a correção ou continuar o tópico em discussão, ignorando o movimento corretivo anterior. Quando essa última atitude é escolhida, diz-se que não houve uptake do aprendiz após o feedback corretivo. No entanto, esse construto não pode ser considerado indicativo de aprendizagem, uma vez que trata da reação imediata do aluno, categorizada em relação a respostas consideradas ideais para aquele turno.

Lyster e Ranta (op cit.), em sua pesquisa, tinham como objetivo analisar as reações dos professores aos erros do aprendiz, categorizando-as em seis diferentes tipos de feedback. Observaram também o efeito que tais reações teriam sobre os aprendizes. Os dados analisados correspondem à observação de quatro turmas de imersão de Francês como L2, 
totalizando 18,3 horas de gravação em áudio. Os resultados apontam que os professores observados forneceram feedback à maioria dos turnos dos alunos que continham erros, sendo que os recasts formaram o tipo de feedback mais utilizado. Recasts foram definidos pelos autores como reformulações feitas pelo professor, corrigindo implicitamente todo ou parte do enunciado do aprendiz ${ }^{1}$. No entanto, em apenas $31 \%$ das correções com recasts houve uptake do aluno. Por outro lado, as elicitações, apontadas como atitudes corretivas do professor que fazem com que o próprio aprendiz tente a (auto)correção, foram pouco usadas, embora sempre provoquem uptake do aprendiz, devido a sua natureza.

Panova e Lyster (2002) realizaram uma investigação com o objetivo principal de examinar os padrões de tratamento do erro, envolvendo a relação entre tipos de feedback e como aprendizes adultos respondem a cada um deles. Para tanto, observaram um grupo de aprendizes de inglês como segunda língua, de nível iniciante, durante três semanas.

Os resultados, de maneira geral, assemelham-se àqueles encontrados no estudo de Lyster e Ranta (op cit.). O professor forneceu algum tipo de tratamento corretivo a 54\% dos turnos dos aprendizes contendo erros, sendo recast a categoria mais utilizada. Apenas $41 \%$ do total dos turnos corrigidos pelo professor são seguidos por uptake dos aprendizes (um índice menor do que aquele registrado nas aulas de imersão). Os autores atribuem esses resultados ao baixo nível de proficiência dos aprendizes, o que impossibilita a negociação da forma (caracterizada pela auto-correção) nessas aulas de L2.

A definição do termo uptake enquanto reação do aprendiz a algum movimento corretivo, no entanto, não é unanimemente aceita na área de aquisição de segunda língua. Ellis, Basturkmen e Loewen (2001), por exemplo, sugerem que essa reação do aprendiz pode seguir outros enunciados do professor desde que eles contenham informações sobre a forma lingüística. Os autores relatam uma pesquisa realizada com o intuito de investigar o uptake do aluno nos episódios de Foco na Forma incidentais, ou seja, não planejados anteriormente. Faz parte do foco específico dessa investigação a influência que o enunciado do professor pode ter sobre o sucesso do uptake do aprendiz. O uptake é considerado bem sucedido, tanto nesse modelo quanto naquele proposto por Lyster e Ranta (1997), quando o enunciado do aprendiz está lingüisticamente correto.

Ellis, Basturkmen e Loewen (2001) conduziram observações em duas turmas de inglês como segunda língua de nível pré-intermediário e intermediário, totalizando 12 horas de atividades comunicativas gravadas em áudio. Nesse período, foram observados 448 episódios de Foco na Forma incidentais. Considerando apenas os episódios nos quais era possível a ocorrência de uptake, esse aconteceu em 73\% dos casos, um índice relativamente alto, comparando com outras pesquisas realizadas em contextos semelhantes. $\mathrm{O}$ índice de sucesso foi igualmente alto: $74 \%$ do total de uptake estavam lingüisticamente corretos. Ellis, Basturkmen e Loewen (op cit.) referem-se, ainda, às principais características dos episódios que levaram a um aumento da ocorrência de uptake bem sucedido. São elas: o fato de ser iniciado pelo próprio aprendiz, estar relacionado primariamente à negociação do sentido e referir-se a problemas lexicais ou gramaticais.

${ }^{1}$ No entanto, ver Nicholas, Lightbown e Spada (2001) para uma visão mais abrangente sobre esse movimento corretivo. 
Pesquisando, ainda, o sucesso dos movimentos de correção dos professores na aula de L2, Lyster (1998) procurou determinar que tipo de feedback corretivo leva ao reparo imediato do erro do aprendiz. Reparo, para este autor, refere-se à reformulação, feita pelo aprendiz, do item incorreto. Assim, o enunciado é considerado reparado quando o aprendiz é capaz de repeti-lo sem erros lingüísticos. A base de dados utilizados para essa investigação é a mesma de Lyster e Ranta (1997): 27 aulas de quatro turmas de imersão em francês. É apontado que os professores preferem usar recasts após erros fonológicos ou gramaticais e, quando deparados com erros lexicais buscam utilizar movimentos que levam à negociação da forma. Foi observado, ainda, que a maioria dos reparos de erros fonológicos foi realizada pelo próprio professor e repetido pelo aprendiz. Por outro lado, a maior parte dos reparos gramaticais e lexicais foi realizada por colegas e pelo aprendiz que cometeu o erro (seguindo a negociação da forma iniciada pelo professor).

Também a investigação a respeito da eficácia dos movimentos corretivos no desenvolvimento da proficiência dos aprendizes tem sido alvo de diversos pesquisadores. A principal pergunta feita é em que medida os diferentes tipos de feedback corretivo utilizados em sala de aula trazem contribuições ao processo de aprendizagem da LE. Grande parte das pesquisas com esse objetivo apresentam considerações específicas sobre o uso de recasts para promover a aprendizagem, pois, conforme reportado pelos estudos anteriores, esse é o movimento corretivo mais utilizado em sala de aula. Para tanto, apenas observações das aulas (base de dados nas pesquisas sobre uptake) não são suficientes, uma vez que se torna necessário testar a proficiência dos aprendizes antes e depois da utilização das práticas corretivas. Desse modo, além dessas investigações, outros dois formatos de pesquisa são conduzidos, quais sejam: (1) experimental, realizada em laboratório, geralmente em díades, utilizando-se de pré-testes, pós-testes e testes postergados e (2) quase-experimental, caracterizada pela mudança no comportamento corretivo do professor em uma sala de aula, seguida de testes aplicados nos alunos.

O estudo conduzido por Havranek (1999) é um exemplo de investigação em sala de aula sobre os efeitos do feedback corretivo na língua utilizada pelo aprendiz. Além da observação dos padrões interacionais e da ocorrência de correção, a autora procurou determinar em que medida os aprendizes conseguiam reconhecer feedback corretivo e se esse reconhecimento poderia implicar em aprendizagem subseqüente. Para tanto, foram investigados 207 aprendizes em oito turmas de inglês como L2 que deveriam responder a questionários no final de cada aula sobre as correções que nela ocorreram, bem como, no final do período de observação, testes sobre os itens corrigidos pelo professor no decorrer da observação. Os resultados revelam que o tipo de feedback mais eficaz é aquele que oportuniza a auto-correção, especialmente quando a forma lingüística é tratada de forma mais explícita.

Outra pesquisa experimental, utilizando o formato de interação em díades (um aprendiz e um falante nativo), foi conduzida por Long, Inagaki e Ortega (1998). Foi comparada a contribuição dos recasts (feedback negativo implícito) e dos modelos de língua (insumo positivo não-reativo ${ }^{2}$ ) no desenvolvimento da proficiência em LE de 24 aprendizes adultos

${ }^{2}$ No original: preemptive positive input. 
de japonês e 30 aprendizes de espanhol. Ainda que apresentando resultados não uniformes, o experimento apontou para a vantagem do uso de recasts em melhoras imediatas na proficiência dos aprendizes (uma vez que o pós-teste foi realizado na mesma sessão do tratamento).

Tanto as investigações em sala de aula, quanto as pesquisas conduzidas em laboratório parecem apontar para a eficácia do uso de recasts para o desenvolvimento do conhecimento do aprendiz sobre a LE. No entanto, parecem afetar essa eficiência fatores como o estágio de desenvolvimento dos aprendizes, a área da língua a ser tratada (lexical ou gramatical, por exemplo) e o item lingüístico específico (Nicholas, Lightbown e Spada, 2001). A utilização bem sucedida desse movimento parece depender também da realização de ênfase no seu uso, a fim de tornar essa correção mais explícita ao aprendiz.

\section{CORREÇÃO DE ERROS: PERSPECTIVA SOCIOCULTURAL}

O crescente interesse da área de aquisição de segunda língua pela teoria sociocultural relaciona-se com a explicação que essa oferece dos processos envolvidos na interação entre indivíduos e, especificamente, na interação que leva ao desenvolvimento de uma LE. Para essa abordagem, a interação em sala de aula deixa de ser apenas um fórum de prática do que foi anteriormente aprendido ou, segundo van Lier (2000), dos significados que migraram para dentro da cabeça do aprendiz. Aprender e usar uma língua deixam de ser dois fenômenos distintos. Conseqüentemente, a aprendizagem ocorre durante atividades contextualizadas e significativas nas quais o aprendiz se engaja. Tanto essa participação na interação verbal quanto a "atividade perceptual e social do aprendiz (...) são centrais para uma compreensão da aprendizagem. Em outras palavras, elas não apenas facilitam a aprendizagem, elas são aprendizagem de uma maneira fundamental"33 (Van Lier, 2000:246).

Sob esse novo paradigma, a pesquisa sobre aquisição de uma língua também sofre alterações, uma vez que se busca compreender o processo de ensino e aprendizagem sob a ótica dos próprios participantes, identificando fatos que podem influenciar no desenvolvimento da nova habilidade. O pesquisador procura, na interação entre professor e alunos, identificar momentos que oportunizem a emergência da aprendizagem, bem como determinar o valor pedagógico de vários contextos e processos interacionais operacionalizados no discurso de sala de aula. O principal foco de investigação é, segundo Donato (1994), observar a co-construção do conhecimento que leva à mudança lingüística, uma vez que a mudança é determinada pelo contexto concreto da interação.

Contudo, ao considerar a co-construção do conhecimento em sala de aula, deve-se levar em consideração uma peculiaridade desse contexto: ele não segue as mesmas regras interacionais dos outros ambientes de interação verbal como uma conversa informal, por exemplo. Professor e aprendizes possuem papéis institucionais determinados e procuram segui-los em suas atividades (Consolo, 2000). São estabelecidas, com base nesses papéis

\footnotetext{
${ }^{3}$ Ênfase no original.
} 
institucionais, expectativas do que é considerado apropriado nesse contexto, bem como tarefas desempenhadas por cada um dos participantes (Hall e Verplaetse, 2000). Ao professor, por ser considerado especialista (expert) no assunto, cabe o papel de estruturar e gerenciar todas as práticas instrucionais realizadas.

Outra tarefa reservada ao professor é oferecer algum tipo de feedback após cada produção do aprendiz, gerando a seqüência conhecida como IRF (iniciação, resposta, feedback). Não raramente, esse último movimento é caracterizado por uma correção (mais ou menos explícita) do enunciado anterior, caso ele contenha um erro. Então, o que, em conversas rotineiras, seria considerado uma quebra das "regras sociais" ou ameaça à face do interlocutor (cf. Schegloff, Jefferson e Sacks, 1977), na sala de aula é aceito como componente intrínseco e até mesmo desejado.

A função da correção de erros na sala de aula, sob uma perspectiva sociocultural, é permitir que os aprendizes saibam os critérios particulares pelos quais seu desempenho está sendo avaliado e comparem suas ações a tais critérios (Hall, 2001). Ela poderia, ainda, ser percebida como uma ajuda do professor que facilite a construção do turno em andamento (van Lier, 1988). Por outro lado, o uso freqüiente desse movimento em sala de aula evidencia o status superior do professor como falante mais competente da língua alvo, explicitando as relações de poder subjacentes a esse contexto.

Corrigir erros na aula de LE seria, portanto, uma atividade social de participação conjunta e negociações significativas entre professor e alunos. Nassaji e Swain (2000:356) defendem que "a eficácia do feedback corretivo não depende do tipo de feedback, mas da maneira pela qual ele se desenvolve na interação e como é negociado entre noviço e expert". É possível perceber, então, que as pesquisas atuais sobre correção de erros deixam uma lacuna nesse aspecto. A classificação já feita dos diferentes movimentos corretivos, bem como a descrição dos efeitos dessas práticas na aprendizagem de LE, não oferecem uma explicação da negociação que se desenvolve em torno da correção de erros.

Um estudo que procurou completar essa lacuna foi conduzido por Nassaji e Swain (2000). O principal objetivo foi examinar quantitativa e qualitativamente se o feedback corretivo fornecido dentro da Zona de Desenvolvimento Proximal (ZDP) do aprendiz poderia aumentar seu conhecimento dos artigos em inglês em oposição aofeedback aleatório e que não leva em consideração a ZDP do aprendiz. Foram realizadas 4 sessões de 40 minutos cada com 2 aprendizes adultos de inglês como L2, nas quais eram realizadas correções de textos escritos anteriormente pelos aprendizes. Tanto os componentes quantitativos quanto os qualitativos da análise sugerem, como principal resultado, que a ajuda fornecida dentro da ZDP foi mais eficaz do que a fornecida aleatoriamente.

Em contexto brasileiro, Gil (1999) desenvolveu um modelo de análise do discurso em sala de aula, especificamente das unidades de foco na forma, sob a perspectiva sociocultural. Com esse objetivo, a autora observou 14 aulas de língua inglesa de uma turma cursando o quarto semestre de um curso de Licenciatura em Letras. Além dessas observações, foram realizadas entrevistas com a professora e alguns alunos para evocar suas percepções a respeito da interação em sala de aula, bem como sua visão sobre alguns episódios ocorridos em aula que envolvessem foco na forma. O modelo de análise do 
discurso de sala de aula proposto por Gil (op cit.) fundamenta-se nos episódios metalingüísticos ${ }^{4}$, classificados de acordo com a estrutura de participação, objetivos pedagógicos, dimensões, focos, tipos e modos das atividades desenvolvidas. Segundo a autora, a dicotomia entre fala com foco na forma e fala comunicativa não é sustentável no uso da língua dessa sala de aula. Além disso, as dimensões metalingüísticas parecem ser essenciais para a implementação da construção conjunta do conhecimento.

A pesquisa apresentada a seguir também procura contribuir para o desenvolvimento de uma análise mais ampla dos fenômenos da sala de aula. Busca-se relacionar os resultados obtidos pelas pesquisas anteriores, que descreveram e categorizaram os movimentos corretivos usados pelos professores, com a perspectiva sociocultural, que propõe uma investigação dos processos significativos envolvidos nessa interação.

\section{O ESTUDO}

Esta pesquisa foi conduzida em uma turma do curso de Licenciatura em Letras Língua Inglesa, cursando o componente curricular Inglês VI de uma universidade no sul do Brasil. O grupo era formado por 21 alunos, com idades entre 20 e 35 anos, sendo que grande parte já atuava como professor de inglês em escolas e cursos privados da região. A professora responsável por essa turma, denominada Paula nessa pesquisa, tem uma ampla experiência de ensino de línguas em diversos contextos, sendo uma defensora do ensino comunicativo. No entanto, além de desenvolver a fluência oral e escrita dos alunos, um dos principais objetivos do semestre, segundo a professora, era aprimorar a acurácia lingüística dos aprendizes, o que tornava esse contexto de pesquisa apropriado aos objetivos deste trabalho.

Foram realizadas observações e gravações em áudio de seis aulas durante os dois últimos meses do segundo semestre letivo de 2003, totalizando 20 horas de gravação das interações verbais que ocorreram entre a professora e a turma como um todo. Após a realização de uma análise prévia dos dados, foram selecionados e transcritos momentos relevantes à análise que ilustrassem os diferentes movimentos de foco na forma observados no decorrer das aulas. Em seguida, o modelo de análise proposto por Gil (1999), especificamente aquele relacionado ao feedback fornecido pelo professor foi adaptado e aplicado aos excertos selecionados.

Esse modelo procura determinar a principal função do feedback corretivo na interação entre professora e alunos. Desse modo, a autora defende que se pode evidenciar, dependendo do tipo de feedback fornecido, se a instrução observada serve como andaime para a produção subseqüente do aprendiz. Em outras palavras, se o professor procura incorporar ou ampliar o enunciado do aprendiz na interação, relacionando-o a outras experiências na língua alvo, e não apenas avaliá-lo por meio do feedback, estar-se-ia criando um diálogo significativo que leva à aprendizagem da LE.

${ }^{4}$ Definidos por Gil (1999:71) como "atividades em sala de aula que possuem um objetivo pedagógico definido e um foco implícito ou explícito em algum aspecto da língua”. 
Dois excertos serão analisados nesta seção como representativos das interações que comumente acontecem na sala de aula observada. Em todos os excertos a turma está envolvida na preparação ou na discussão dos resultados de atividades realizadas em duplas ou grupos menores. Os alunos, nessas aulas, envolvem-se em atividades comunicativas de interação oral ou escrita e também em atividades de reconhecimento e produção de estruturas gramaticais específicas, geralmente realizadas na modalidade escrita da língua, por meio da manipulação de sentenças e textos menores. Durante esses momentos, mesmo nas atividades que possuem um enfoque formal subjacente ou motivador, parece ser da professora a função de fazer com que a atenção dos alunos seja voltada para a forma lingüística explicitamente, sendo raras as ocasiões nas quais os alunos iniciam esse foco na interação. Em outras palavras, apesar do propósito da atividade, em muitas ocasiões, ser a manipulação da forma lingüística, os alunos dificilmente iniciam espontaneamente discussões sobre aspectos formais da língua. Observe-se o excerto a seguir, no qual a professora procura explicar como a atividade seguinte deve ser realizada, evocando exemplos dos próprios alunos.

\section{Excerto 01 ${ }^{5}$}

01 Paula: so, the first question, what kind of people do you like? $(0,8)$ so you have to answer (.) following this model yes? Following this exponent $(0,6)$. I like people who?

04 Michele: likes dance.

05 Cláudia: are friend[ly.

06 Paula: [like, people who like to dance?

07 Carla: likes to dance.

08 Paula: $\underline{\text { like. }}$

09 Carla: li[ke?

10 Paula: [because it's people.

\footnotetext{
${ }^{5}$ As convenções utilizadas nas transcrições são as seguintes: números entre parênteses $(0,8)$ : tempo de silêncio ponto entre parênteses (.): silêncio de até 0,5 segundos texto sublinhado: ênfase [colchetes: fala em sobreposição ((texto entre dois parênteses)): comentários de transcrição dois pontos seguidos: prolongamento de vogal
} 
11 Alunos: oh yeah! ((demonstram surpresa))

12 Paula: people, uh hum, OK? (.) What else?

13 Carmen: who is calm.

14 Paula: who?

15 Carmen: is calm.

16 Carla: are calm.

17 Carmen: are calm.

18 Paula: ye[ah:: people, exactly.

19 Carmen: [ah, é people.

Esse excerto pode ser classificado como tendo um foco na forma explícito, uma vez que Paula lança mão do conhecimento metalingüístico dos alunos para negociar a forma verbal apropriada à situação, ou seja, ela utiliza o conhecimento da estrutura gramatical que os alunos já possuem para justificar sua correção. O resultado discursivo dessa correção é um diálogo entre professora e alunos, no qual não há predominância no tempo de fala de nenhum dos envolvidos. Tal equilíbrio, além de possibilitar aos estudantes oportunidades mais estendidas de produção, indica que Paula coloca-se no papel de par interacional que dá suporte aos outros participantes durante a produção de suas falas. No começo do excerto (linhas 01 a 03) percebe-se a preocupação de Paula em garantir que os alunos utilizem o modelo fornecido a fim de praticar a forma gramatical em foco. Em seguida, com a realização de uma correção na linha 06 , a professora procura re-contextualizar a forma sugerida por Michele, utilizando-a para garantir que os demais alunos compreendam a maneira considerada apropriada de realizar a tarefa. É interessante ressaltar que, na linha 05, Cláudia oferece uma sugestão que poderia ser considerada correta pela professora. No entanto, Paula não se volta para essa contribuição, preferindo explicitar o modelo de língua considerado ideal para tal atividade a partir da correção explícita do enunciado de Michele.

Apesar de corrigir explicitamente e garantir a compreensão dos alunos de que o enunciado de Michele contém uma inadequação, Paula não o rejeita. Pelo contrário, a sugestão feita pela aluna é incorporada ao discurso da professora, integrando-se como resposta possível à proposta de trabalho. Para tanto, dois diferentes mecanismos são utilizados: a repetição, com mudança, do enunciado da aprendiz (denominado recast nos 
FREUDENBERGER \& LIMA- A correção de erros como co-construção...

estudos anteriores) e a ênfase na forma verbal sendo corrigida (acrescida da entonação de pergunta). Também a atitude de Carla contribui para que a correção torne-se explícita, uma vez que ela parece corrigir a fala de Paula (linha 07). A partir da contribuição dessa aluna, Paula fornece uma explicação metalingüística para sua correção e a inadequação da forma previamente sugerida (linha 10).

Na interação subseqüente pode-se visualizar que tal explicação ocasionou, para alguns alunos, um grau maior de atenção à forma lingüística. As contribuições de Carla evidenciam esse aumento na consciência quanto à forma lingüística. Primeiramente, ela parece compreender que a pergunta de Paula subseqüente à contribuição de Carmen (linha 14) procura indicar uma inadequação gramatical e possibilitar a auto-correção. Em seguida, ao perceber que a colega volta-se apenas para o conteúdo semântico do seu enunciado (linha 15), Carla oferece uma alternativa, corrigindo a forma lingüística (língua 16). Essa correção é reforçada pela professora, que fornece a mesma explicação ao erro cometido (linha 18).

No excerto seguinte, pode-se evidenciar, novamente, que a correção do enunciado, seguida de explicação metalingüística, parece aumentar a atenção à forma lingüística.

\section{Excerto 02}

01 Paula: then, the next one, Miguel, please, example e.

02 Miguel: I read ((/ri:d/)) the book that your professor wrote.

03 Paula: it's all in the past people, so I?

04 Inês: $\operatorname{read}((/ \mathrm{red} /))$.

05 Paula: $\underline{\text { read }}((/ \mathrm{red} /))$ yes? All in the past, $\underline{\mathrm{I} \text { read. }}$.

06 $(\ldots)$

07 Paula: so people, we also have something else here to pay attention to, yeah?

08 Let's take a look there in example k, Liane.

09 Liane: I:: (.) read ((/riid/)) the book that was (.) published ((/pubjif'ed/)) last

$10 \quad$ year. I read $((/ \mathrm{red} /))$ ? 
11 Paula: y[e:::s, very good.

12 Liane: [I read $((/ \mathrm{red} /))$ the book.

13 Paula: and published $((/ \mathrm{p} \wedge$ b $1 \mathrm{i} \mathrm{d} \mathrm{d} /))$.

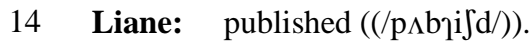

15 Paula: good.

Liane demonstra que a explicação metalingüística oferecida por Paula (linha 03) e a correção realizada por Inês (linha 04), seguindo tal explicação, possibilitou uma consciência maior da pronúncia do passado do verbo em questão (linha 10). Assim, o foco da interação aqui reportada é fonológico, relacionado à forma gramatical do verbo. Note-se que o elemento motivador da interação é estritamente gramatical (a exemplo do excerto anterior), envolvendo a explicação da forma lingüística para realização posterior de atividades de manipulação de tal aspecto. No entanto, devido a um erro de pronúncia ocorrido durante a leitura dos exemplos, a atenção é desviada para os aspectos fonológicos envolvidos.

Quanto às características da interação, nota-se que, apesar de haver uma diferença no tempo de fala da professora e dos alunos durante a explicação do ponto gramatical em questão (relative clauses), durante a realização das correções (linhas 03 a 05 e 10 a 14), esses padrões tornam-se mais igualitários, podendo-se dizer que há, novamente, um equilíbrio entre as contribuições de Paula e dos alunos envolvidos. Toda a interação é perpassada por um foco na forma explícito, mesmo nos enunciados não corretivos. Ao contrário do que foi observado no excerto 01 , a professora rejeita, nessa interação, a forma produzida por Miguel, motivando-o, indiretamente, a reformular seu enunciado (linha 03). É Inês, no entanto, que leva a cabo a correção iniciada por Paula (linha 04), restando a essa confirmar a sugestão de Inês e incorporá-la ao seu discurso (linha 05). Para Gil (1999), a combinação desses fatores (foco metalingüístico explícito e rejeição da forma produzida pelos alunos) caracteriza uma instrução tradicional que não prioriza a construção conjunta do enunciado e, segundo a qual, a função do professor não é apoiar a produção do aprendiz.

Entretanto, a correção realizada parece ter trazido subsídios para possibilitar a autocorreção de Liane na realização da leitura subseqüente (linhas 10 e 12). Note-se que, dos dois erros de pronúncia realizados, ela volta-se para aquele recém discutido, sendo necessário que Paula aponte e corrija explicitamente o outro (linha 13). Pode-se especular, então, que a correção de uma forma lingüística, mesmo quando rejeitando a produção anterior, pode contribuir para o desenvolvimento da consciência lingüística dos aprendizes e fornecer subsídios para a aprendizagem subseqüente de uma LE. 


\section{CONSIDERAÇÕES FINAIS}

Compreender a eficácia da correção dos erros lingüísticos é uma preocupação não somente dos pesquisadores da área da aquisição de segunda língua ou língua estrangeira como também, e principalmente, dos professores envolvidos no processo de aprender e ensinar uma língua. Entendemos que uma análise mais detalhada de excertos da interação revela-se essencial, já que possibilita uma percepção qualitativa de aspectos relevantes relacionados a essa prática. É também por meio de uma análise detalhada que conceitos relevantes à teoria sociocultural, como andaimento e ZDP, operacionalizam-se nos dados de sala de aula.

Com relação à primeira pergunta da pesquisa, que questiona a função desempenhada pela correção de erros na interação entre professor e alunos em sala de aula, observa-se que a professora procura tornar a contribuição feita pelo aprendiz uma parte integrante do discurso de sala de aula. Ela freqüentemente incorpora os enunciados dos alunos na sua própria explicação. $\mathrm{O}$ fato de conterem inadequações lingüísticas não impede que sejam incorporados, já que, ao realizar a correção, Paula recontextualiza as contribuições feitas pelos alunos.

Uma segunda função do feedback relacionado à forma lingüística na sala de aula é fornecer um modelo da língua alvo para o aprendiz. Nesse sentido, mesmo quando rejeitando o enunciado produzido pelo aluno, a professora o faz relacionando a forma inapropriada ao conhecimento prévio dos alunos. Assim agindo, a professora parece oportunizar, por meio do diálogo, um espaço de co-construção do conhecimento da língua alvo. Essa característica da interação da sala de aula, particularmente da correção da forma lingüística, relaciona-se diretamente com a segunda pergunta de pesquisa proposta neste trabalho, qual seja: a interação que acontece a partir da correção de erros pode representar momentos de co-construção, entre professor e aprendizes, do conhecimento da LE? Foi percebido, na análise dos dados coletados, que as instâncias de construção do conhecimento a respeito da LE não são exclusivas à instrução caracterizada como ideal por Gil (1999). Mesmo a interação que se desenrola com um objetivo explicitamente formal, somada à rejeição da forma lingüística produzida pelo aluno, pode caracterizar a construção de um andaime ao desenvolvimento da linguagem do aprendiz.

Ainda que não seja possível afirmar que, ao perceber uma correção dos erros lingüísticos, o aprendiz aumente seu conhecimento sobre a $L 2$ ou aprenda o item em questão, foi possível observar, nos excertos, um aumento no grau de atenção à forma. Ao possuir maior consciência lingüística, especula-se que o aluno construa seus enunciados de maneira mais apropriada ao contexto (mesmo que imediato). Parece-nos, então, que a correção dos erros lingüísticos, quando busca incorporar o enunciado do aprendiz ao discurso de sala de aula ou ao conhecimento/experiência de língua construído anteriormente, pode servir de apoio ao desenvolvimento lingüístico do aprendiz, auxiliando na construção desse conhecimento. 


\section{REFERÊNCIAS BIBLIOGRÁFICAS}

ALLWRIGHT, D.; BAILEY, K. (1991). Focus on the Language Classroom: an introduction to classroom research for language teachers. Cambridge University Press.

CONSOLO, D. (2000). Teachers' action and student oral participation in classroom interaction. In: Hall, J. e Verplaetse, N. Second and Foreign language acquisition through classroom interaction. Mahwah: Lawrence Erlbaum, p.91-107.

CHAUDRON, C. (1988). Second Language Classrooms: research on teaching and learning. Cambridge University Press.

DONATO, R. (1994). Collective scaffolding in second language learning. In: Lantolf, J. e Appel, G. (eds.). Vygotskian approaches to second language research. Norwood: Ablex, p. 33-56.

DOUGHTY, C.; WILLIAMS, J. (1998). Focus on Form in Classroom Second Language Acquisition. Cambridge University Press.

ELLIS, R. (1994). The study of second language acquisition. Oxford: Oxford University Press.

ELLIS, R., BASTURKMEN, H.; LOEWEN, S. (2001). Learner Uptake in Communicative ESL Lessons. Language Learning, 51(2), p. 281-318.

FREUDENBERGER, F.; LIMA, M. (2003). Relacionando Crenças e Tratamento do Erro na Aula de Língua Estrangeira: um estudo de caso. Revista Formas e Linguagens, Editora UNIJUÍ. vol. 6, p. 42-53.

GIL, G. (1999). The metalinguistic dimensions of the foreign language classroom: discourse perspectives on focus-on-form episodes. Tese de Doutorado: Universidade Federal de Santa Catarina.

HALL, J.; VERPLAETSE, N. (2000). Second and Foreign language acquisition through classroom interaction. Mahwah: Lawrence Erlbaum.

HALL, J. (2001). Methods for Teaching Foreign Language: creating a community of learners in the classroom. Columbus: Merril Prentice House.

HARLEY, B. (1993). Instructional strategies and SLA in early French immersion. Studies in Second Language Acquisition, v. 15, 245-260.

HAVRANEK, G. (1999). The effectiveness of corrective feedback: preliminary results of an empirical study. Acquisition et Interaction en Langue Étrangère, v.2, p. 189-206.

KRASHEN, S. (1982). Principles and Practice in Second Language Acquisition. Oxford: Pergamon.

LANTOLF, J.; APPEL, G. (1994). Vygotskian approaches to second language research. Norwood: Ablex.

LIGHTBOWN, P.; SPADA, N. (1990). Focus-on-Form and Corrective Feedback in Communicative Language Teaching: effects on second language learning. Studies in Second Language Acquisition, 12, p. 429-448.

LIMA, M. D. S. (2002). Corrective feedback and interaction: the negotiation of form in a Brazilian EFL classroom. Paper presented at the Canadian Association of Applied Linguistics Conference, University of Toronto, May. 
FREUDENBERGER \& LIMA- A correção de erros como co-construção...

LONG, M., INAGAKI, S.; ORTEGA, L. (1998). The Role of Implicit Negative Feedback in SLA: models and recasts in Japanese and Spanish. The Modern Language Journal, v. 82, p. 357-371.

LYSTER, R. (1998). Negotiation of form, recasts, and explicit correction in relation to error types and learner repair in immersion classrooms. Language Learning, 48, 183-218.

LYSTER, R.; RANTA, L. (1997). Corrective feedback and learner uptake: negotiation of form in communicative classrooms. Studies in Second Language Acquisition, v. 19, p. 37-66.

LYSTER, R., LIGHTBOWN, P.; SPADA, N. (1999). A response to Truscott's "What's wrong with oral grammar correction. The Canadian Modern Language Review, v. 55, p. 457-460.

MENTI, M. M. (2003). Efeito de dois tipos de feedback corretivo - recast e elicitação - no desempenho de alunos de inglês como língua estrangeira. Dissertação de Mestrado. PPG/Letras da Universidade Federal do Rio Grande do Sul.

NASSAJI, H.; SWAIN, M. (, 2000). A Vygotskyan perspective on corrective feedback in L2: the effect of random versus negotiated help on the learning of English articles. Language Awareness, v.9, n.1, p. 3451 .

NICHOLAS, LIGHTBOWN, P.; SPADA, N. (2001). Recasts as feedback to language learners. Language Learning, v. 51, n. 4, p. 719-758.

PANOVA, I.; LYSTER, R. (2002). Patterns of corrective feedback and uptake in an adult ESL classroom. Tesol Quarterly, v. 36, n. 4.

SCHEGLOFF, E. JEFFERSON, G.; SACKS, H. (1977). The preference for self-correction in the organization of repair in conversation. Language n. 53, p. 361-382.

van LIER, L. (1988). The Classroom and the Language Learner: ethnography and second-language classroom research. Longman.

. From input to affordance: social-interactive learning from an ecological perspective. In: Sociocultural theory and second language learning. Oxford University Press, 2000, p.245-260. 